\section{Modification of multilayered TiAIN/TiN coating by nanosecond and picosecond laser pulses}

To cite this article: B Gakovi et al 2009 J. Opt. A: Pure Appl. Opt. 11015601

View the article online for updates and enhancements.

\section{Related content}

- $\frac{\text { Surface modification of titanium nitride film }}{\text { by a picosecond Nd:YAG laser }}$
B Gakovi, M Trtica, D Batani et al.
- Effects of the pulse duration in laser
$\frac{\text { modification of nano-sized WTi film on }}{\text { Sisubstrate }}$
Suzana Petrovi, D Peruško, D Milovanovi
et al.
- Laser-induced structural and composition
$\frac{\text { modification of multilayered Ni/Ti thin film }}{\text { in air and liquids }}$
Suzana Petrovi, Branislav Salati, Davor
Peruško et al.

Recent citations

- Wear Behavior of TiAIN and CrAIN
$\frac{\text { Coatings Deposited by TRD Process on }}{\text { AISI D2 Steel }}$
B. KInc et al
- Femtosecond laser modification of
$\frac{\text { multilavered TiAIN/TiN coating }}{\text { B. Gakovic et al }}$
- Effects of the pulse duration in laser
$\frac{\text { modification of nano-sized WTi film on Si }}{\text { substrate }}$
Suzana Petrovi et al




\title{
Modification of multilayered TiAIN/TiN coating by nanosecond and picosecond laser pulses
}

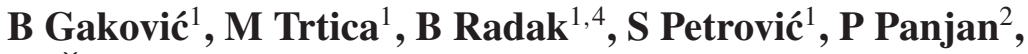 \\ M Čekada ${ }^{2}$, T Desai ${ }^{3}$ and D Batani ${ }^{3}$ \\ ${ }^{1}$ Vinča Institute of Nuclear Sciences, POB 522, 11001 Belgrade, Serbia \\ ${ }^{2}$ Jožef Stefan Institute, Jamova 39, 1000 Ljubljana, Slovenia \\ ${ }^{3}$ Dipartimento di Fisica 'G Occhialini', Università degli Studi di Milano Bicocca, \\ Piazza della Scienza 3, I-20126 Milano, Italy \\ E-mail: bradak@vinca.rs
}

Received 10 November 2008, accepted for publication 3 December 2008

Published 30 December 2008

Online at stacks.iop.org/JOptA/11/015601

\begin{abstract}
A multilayered TiAlN/TiN coating deposited on $\mathrm{H} 11$ work-steel was irradiated by a TEA $\mathrm{CO}_{2}$ laser (ns pulses) and a Nd:YAG laser (ps pulses), and the effects compared. The coating was $2.17 \mu \mathrm{m}$ thick and consisted of 45 layers. The laser-induced modifications showed dependence on laser pulse duration, pulse count and laser wavelength. The conditions for coating ablation in both cases were determined. The experiment has revealed laser-induced periodic surface structures (LPSS) on nanometre and micrometre scales, depending on the laser wavelength used. Sample surfaces were characterized before and after laser irradiation by an optical microscope, scanning electron microscope (SEM), focused ion beam (FIB) microscope and profilometry.
\end{abstract}

Keywords: surface modification, TiAlN coating, nanosecond laser, picosecond laser, crater formation

(Some figures in this article are in colour only in the electronic version)

\section{Introduction}

The ternary coating system of titanium-aluminium-based nitride (TiAl)N is attractive due to its significant enhancement of oxidation resistance and mechanical properties with respect to TiN [1]. Incorporation of aluminium in a TiN film improves the oxidation behaviour, i.e. TiAlN starts to oxidize above $700{ }^{\circ} \mathrm{C}$, whereas oxidation of TiN begins at $550^{\circ} \mathrm{C}$. In addition, multilayered coatings have some advantages over single layers, as they combine the properties of several materials and show some new properties [2-4]. The numerous interfaces formed amongst individual layers of a multilayered coating cause a drastic increase in hardness and strength. Due to the high hardness and brittleness of the coating, its mechanical micro-structuring is difficult, and laser beam treatment is one of the possible solutions. Also, surface patterning in

\footnotetext{
4 Author to whom any correspondence should be addressed.
}

nanotechnological applications is desirable, and laser beams are commonly used for this purpose [5]. In the case of laser pulse durations longer than a few tenths of a picosecond, laser-induced processes are commonly considered as thermally activated, the result of electron-phonon coupling, typically on a timescale of $10-12$ to $10-11 \mathrm{~s}$. With low to medium laser pulse intensities, the laser beam can just be considered as a heat source for surface and bulk temperature rise. At higher pulse intensities, vaporization of the surface starts, a vapour plume above the surface is formed and further increase induces ionization of the vaporized material, i.e. formation of plasma that can cause material ablation, etc $[5,6]$. Thermal effects are expressed in cases of thin film/coating modifications by nanosecond laser pulses, and there are several advantages in material processing with shorter laser pulses [7, 8]. Picosecond laser pulses are better for a more localized surface modification because of negligible collateral thermal damage and the high 


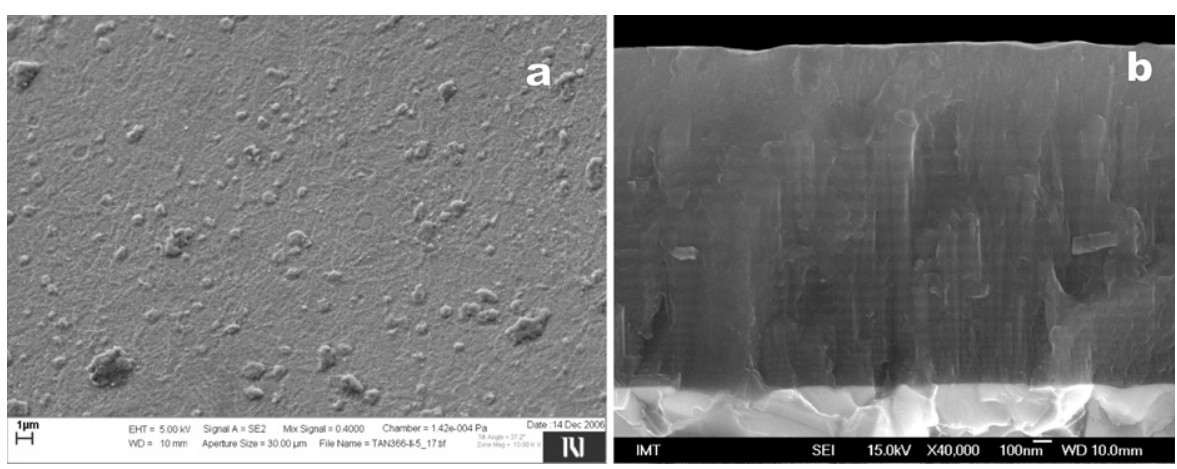

Figure 1. SEM analysis of TiAlN/TiN multilayered coating (total thickness $2.17 \mu \mathrm{m}$ ) deposited on the AISI H11 steel substrate (before laser irradiation). (a) The coating surface and (b) cross section of the coating.

precision of processing. Short laser pulse modification of solids has been largely used in the past decade, especially in nanotechnology applications. Experimental data on the interaction of picosecond laser pulses with thin films are scarce in the literature [9-11], in contrast to nanosecond pulse interactions [12-14].

Studying of interactions of laser beams with hard coatings has importance both in fundamental and applied research. We presently compare the effects of two significantly different lasers on a multilayered TiAlN/TiN coating deposited on a steel substrate. One is an Nd:YAG laser system with 40 ps pulses at a wavelength of $532 \mathrm{~nm}$ and the other is a TEA $\mathrm{CO}_{2}$ gas laser with 100 ns pulses (FWHM).

\section{Experiment}

The target for laser beam irradiation was a multilayered TiAlN/TiN coating deposited on polished hot work tool steel H11 plates in a commercial device CemeCon 800 [15]. The layered structure of the coating was achieved by sequential exposure of the polished substrate to vapour fluxes emitted from cathodes, titanium plates with embedded aluminium. The procedure coincides of three parts: heating of steel substrates, ion etching of substrate in plasma (cleaning) and deposition by sputtering of the metallic target in the reactive atmosphere of nitrogen. The total coating thickness was $2.17 \mu \mathrm{m}$ and consisted of 45 alternating TiAlN/TiN layers. The final layer, $0.5 \mu \mathrm{m}$ thick, was TiAlN. The modulation period of the multilayered structure was about $80 \mathrm{~nm}$.

One of the two lasers used was an active-passive modelocked Nd:YAG system. It is made up of a laser oscillator, an amplifier and a nonlinear crystal $\left(\mathrm{KD}^{*} \mathrm{P}\right)$ for second harmonic generation [11, 16]. A pulse duration of about $40 \mathrm{ps}$ is obtained by using a saturable absorber dye and an acoustooptic standing wave modulator. Linearly polarized laser pulses at a wavelength of $532 \mathrm{~nm}$ were used. Laser fluencies, $F$, at the target were 0.5 and $11 \mathrm{~J} \mathrm{~cm}^{-2}$. The other laser was a TEA $\mathrm{CO}_{2}$ laser [17], which operated with a non-typical $\mathrm{CO}_{2} / \mathrm{N}_{2} / \mathrm{H}_{2}$ (1 bar) gas mixture at a wavelength of $10.6 \mu \mathrm{m}$. The laser pulse consisted of an initial spike of 100 ns (FWHM) and a tail of $2 \mu \mathrm{s}$. Typical laser pulse energy was $70 \mathrm{~mJ}$ and the corresponding fluence $F=13 \mathrm{~J} \mathrm{~cm}^{-2}$. Transversally, the laser had a multimode output.
Sample irradiations were performed with laser beams focused by a quartz lens of $12 \mathrm{~cm}$ focal length (Nd:YAG laser) and a $\mathrm{KBr}$ lens of $6 \mathrm{~cm}$ focal length (TEA $\mathrm{CO}_{2}$ laser). The angle of incidence of the laser beam with respect to the surface plane was $90^{\circ}$. The irradiation was carried out in air at a pressure of 1013 mbar and relative humidity of $60 \%$. A typical pulse repetition rate was $2 \mathrm{~Hz}$.

Various analytical techniques were used for characterization of the sample before and after laser irradiation. The phase composition and crystalline structure of the TiAlN/TiN coating was verified by $\mathrm{x}$-ray diffraction $(\mathrm{Cu} \mathrm{K} \alpha$ radiation $)$. Surface morphology of the samples was monitored by an optical microscope (OM), scanning electron microscope (SEM) and a focused ion beam (FIB) microscope. The SEM was coupled to an energy-dispersive analyser (EDAX) for determining sample surface composition. A profilometer was used to characterize topological changes in the irradiated area.

\section{Results and discussion}

Before laser irradiation, the chemical composition of the TiAlN/TiN coating was carried out by the SEM/EDAX. The results were: Ti 51.67\%; N 26.79\%, Al 18.15\% (O 2.65\% and $\mathrm{Fe} 0.83 \%$ ). The single-phase face-centred cubic (fcc) structure of the coating was confirmed by XRD analysis. The coating showed preferential orientation (111), i.e. it is the same as individual components of the bilayer (TiAlN/TiN). An SEM analysis, figure 1(a), revealed surface micro- and nanodefects. Spherical droplet/cone structures above the surface were typically $0.5 \mu \mathrm{m}-1 \mu \mathrm{m}$ wide (figure 1 (a)). Less expressed, but also present, were shallow craters about $1 \mu \mathrm{m}$ in width. The XRD and SEM analyses have verified coating grain dimensions of less than $50 \mathrm{~nm}$. Cross-sectional SEM of the coating in figure 1(b) shows visible alternating brightness due to individual layers of TiN and TiAlN.

The irradiation of the multilayered coating was done with sets of successive laser pulses delivered to the same spot of the target surface. The pulse count $(N)$ varied from 1 to 100 $(N=1,2,5,30,50$ and 100) in the case of the Nd:YAG laser, and 1 to 660 pulses $(N=1,2,5,33,50,100$ and 660) with the TEA $\mathrm{CO}_{2}$ laser. The laser pulse energy density (fluence), $F$, was kept constant. Only 30 pules of the Nd:YAG laser at 

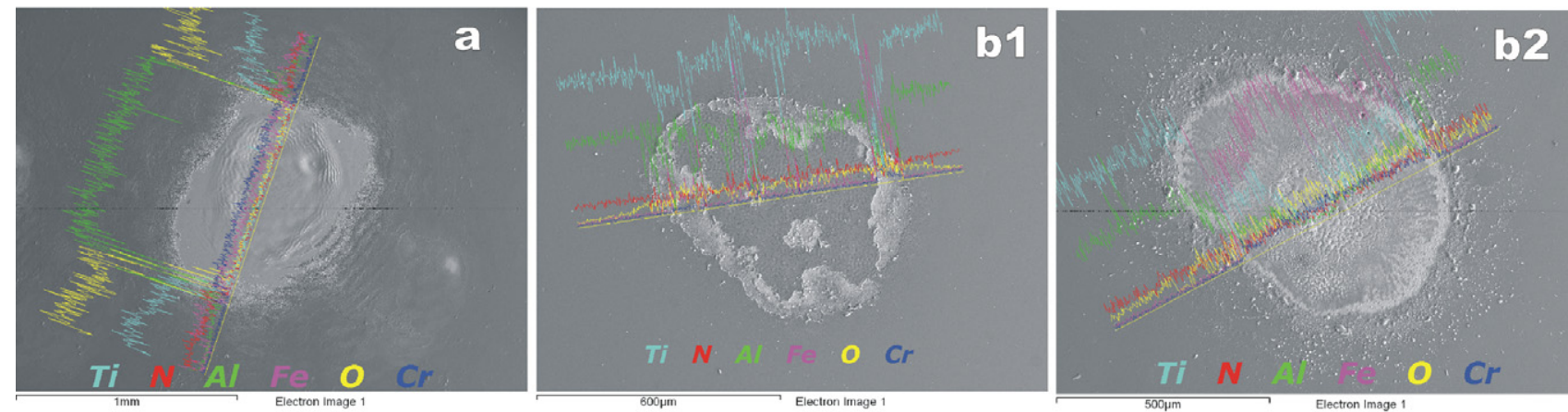

Figure 2. SEM/EDAX compositional analysis of laser-irradiated TiAIN/TiN multilayered coating deposited on steel substrate: (a) Nd:YAG laser $\left(F=11 \mathrm{~J} \mathrm{~cm}^{-2}\right), 100$ pulses and (b) TEA CO 2 laser $\left(F=13 \mathrm{~J} \mathrm{~cm}^{-2}\right)$ : (b1) after 100 pulses and (b2) after 660 pulses.
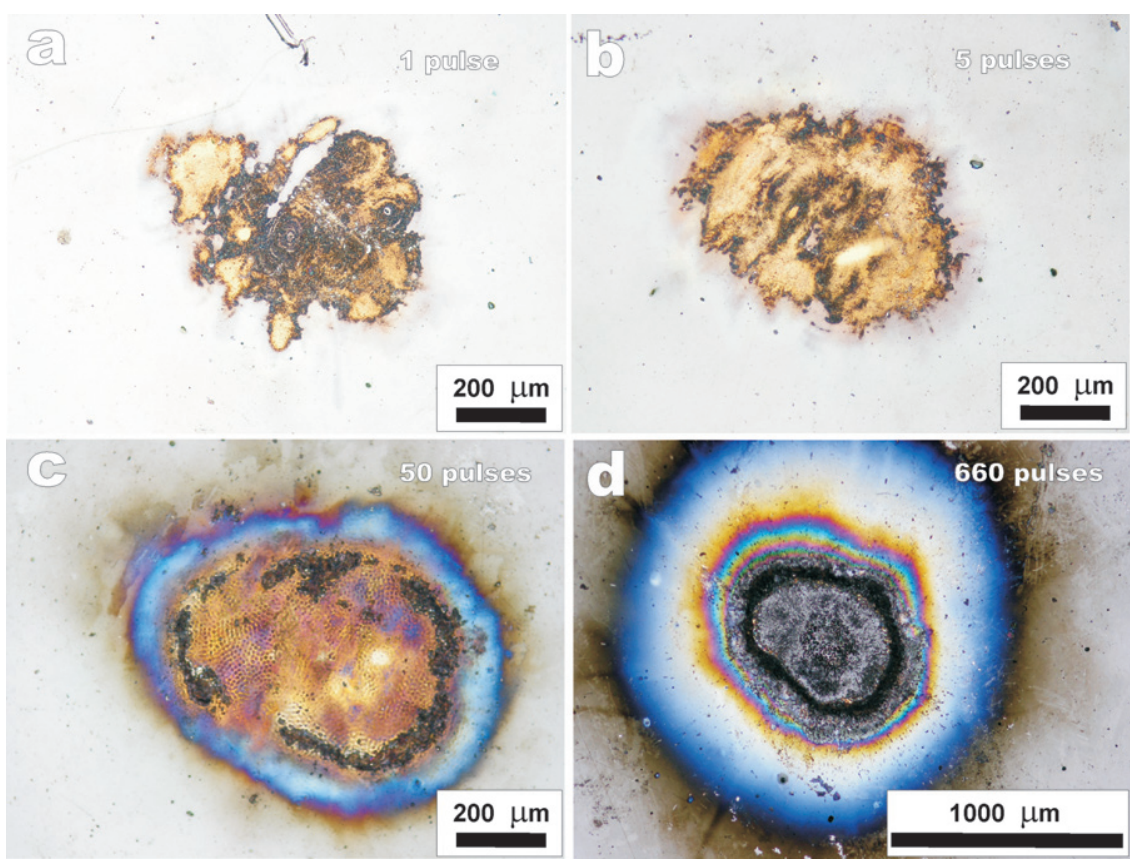

Figure 3. Optical microscopic images of the damage spots created by the TEA $\mathrm{CO}_{2}$ laser at fluence $F=13 \mathrm{~J} \mathrm{~cm}^{-2}$.

$F=11 \mathrm{~J} \mathrm{~cm}^{-2}$ were sufficient to remove the coating from the substrate, compared with 660 pulses needed for the same effect with the TEA $\mathrm{CO}_{2}$ laser. This is visible in the SEM/EDAX analysis presented in figure 2 , as the appearance of $\mathrm{Fe}$ across the whole irradiated spot.

\subsection{TEA $\mathrm{CO}_{2}$ laser effects}

With the TEA $\mathrm{CO}_{2}$ laser one laser pulse was sufficient to produce visible surface changes, as documented by optical microscopy, figure 3(a). Increasing the pulse count to 100 led to noticeable enlargement of the damage spot size, but without complete coating removal from the substrate. After 50 pulses, formation of coloured rings started (figure 3(c)), implying complex oxidation. Coating removal occurred at 660 laser pulses, figure 3(d). Irradiation with the TEA $\mathrm{CO}_{2}$ laser was accompanied by plasma appearance after the first and successive pulses.

A detailed SEM analysis, figure 4, revealed periodic surface structures (PSS) at micrometre level. These PSS are clearly recognizable in the central region (100 pulses, figure 4(a2)), with indications even on the steel substrate after coating removal (660 pulses, figure 4(b2)). The periodicity of these structures is about $10 \mu \mathrm{m}$, close to the laser wavelength. This indicates that the cause of their formation are surface electromagnetic waves (SEW) [18-23]. The fact that they are not parallel is due to the transversal profile of the laser being multimode.

It is well known that, with nanosecond TEA $\mathrm{CO}_{2}$ laser pulses, depending on fluence, the radiation is converted into thermal energy, which generates a series of effects such as heating, melting, vaporization of the molten material, dissociation or ionization of the vaporized material, and shock waves in the vapour and the solid. With complex targets, as is the case here, the difference in thermal expansion coefficients between the TiAlN/TiN multilayer coating and the steel substrate generates additional stress at the interface. A direct consequence of this is the appearance of partial coating exfoliation, visible in the present SEM images as well (figure 4(a2)). 

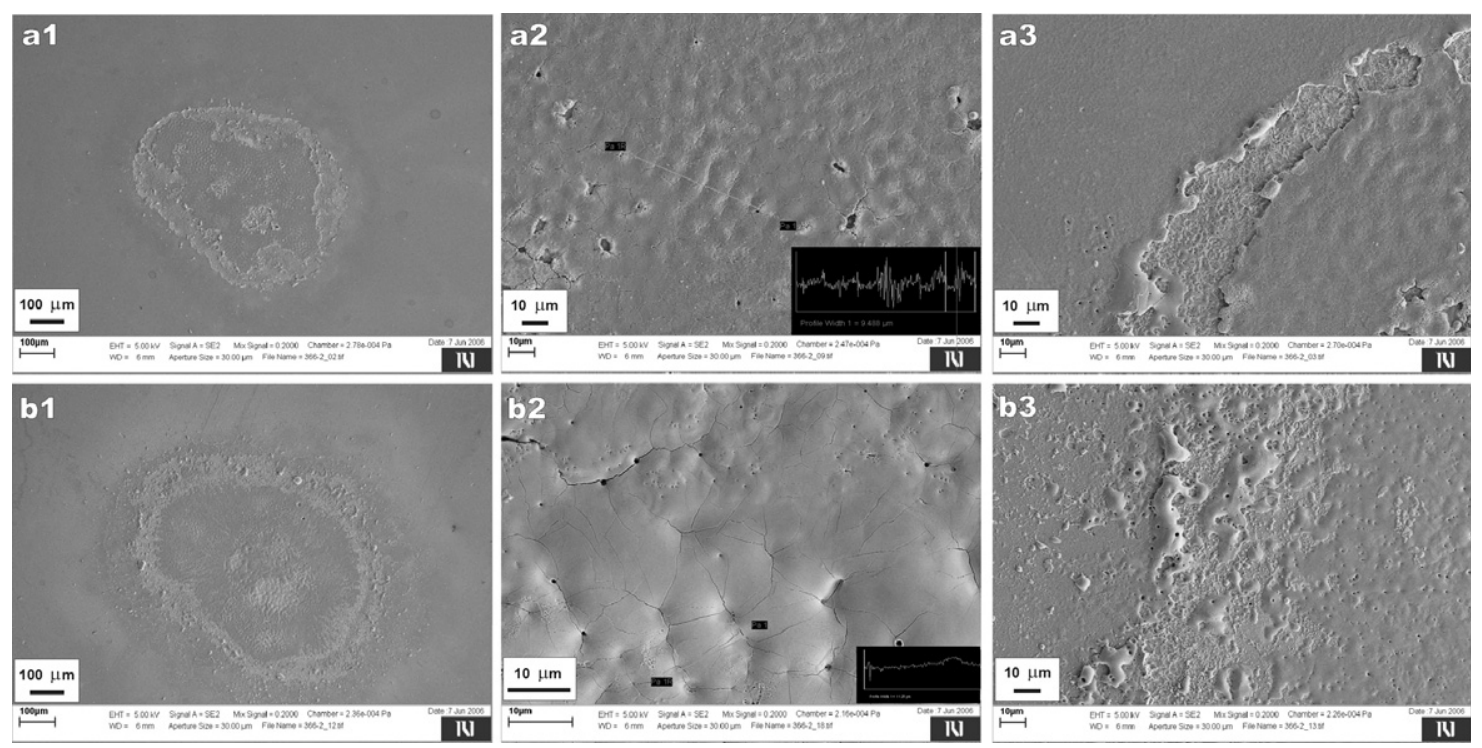

Figure 4. SEM analysis of the damage spot after TEA $\mathrm{CO}_{2}$ laser action: (a) after 100 pulses (a1—entire spot; a2 — spot centre with periodical structures; a3 - spot periphery) and (b) after 660 pulses (b1—entire spot; b2—spot centre; b3—detail at spot periphery); $F=13 \mathrm{~J} \mathrm{~cm}^{-2}$.

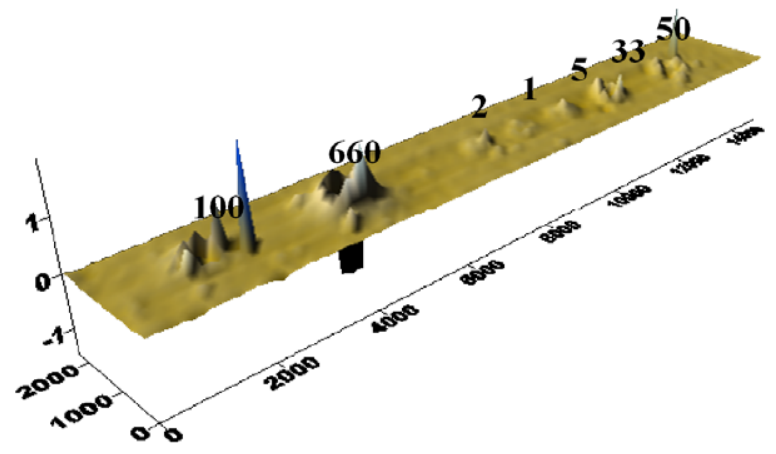

Figure 5. Profilometric 3D view of the sample after $\mathrm{TEA} \mathrm{CO}_{2}$ laser irradiation, $F=13 \mathrm{~J} \mathrm{~cm}^{-2}$. Numbers of laser pulses at each spot are indicated.

A profilometric topological analysis, figure 5, showed that the material protruded above the sample surface at any number of accumulated laser pulses. Only in the case of 660 pulses was the ablation clear and a $1.6 \mu \mathrm{m}$ deep crater was formed.

\subsection{Nd:YAG laser effects}

The Nd:YAG laser was used at the $532 \mathrm{~nm}$ wavelength and two different fluences, $F=0.5 \mathrm{~J} \mathrm{~cm}^{-2}$ (the effects shown in figure 6) and $F=11 \mathrm{~J} \mathrm{~cm}^{-2}$ (the effects shown in figure 7).

The lower fluence of $0.5 \mathrm{~J} \mathrm{~cm}^{-2}$-induced formation of parallel nanometre periodic surface structures (PSS), with a periodicity of $400 \mathrm{~nm}$, close to the laser wavelength used, across the whole damage spot, and perpendicular to the laser electrical field, figure 6(a2). As in the case of the TEA $\mathrm{CO}_{2}$ laser, this indicates that the origin of the structures are the SEW formed at the surface. The FIB analysis, figure 6(a3), revealed that these structures were confined to the coating surface only, without affecting the interface with the metal substrate. We have earlier obtained identical periodicity with the same laser on a different type of sample-bulk Ti6Al4V alloy [24].

Our results showed that the damage threshold (defined as the minimum laser fluence required for creating detectable damage on the target after one pulse) for the TiAlN/TiN multilayered coating with the Nd:YAG $(532 \mathrm{~nm})$ laser was about $0.3 \mathrm{~J} \mathrm{~cm}^{-2}$.

Morphological changes of the TiAlN/TiN coating induced by the fluence of $11 \mathrm{~J} \mathrm{~cm}^{-2}$, with 10 and 100 accumulated laser pulses, are presented in figure 7. The entire laser spot after 10 pulses is presented in figure 7(a). At the centre (figure 7(a2)) a superficially ablated area can be recognized, with the appearance of hydrodynamic features like resolidified droplets. Parallel periodic structures of the same periodicity $(400 \mathrm{~nm})$ as in the former case are visible too, on the periphery, figure 7(a3). Irradiation with 100 pulses (figure 7(b)) resulted in total coating ablation in the central area and further appearance of periodic structures at the periphery on the remaining coating, with the same periodicity of $400 \mathrm{~nm}$, but more clearly defined. It is important to note that, at this fluence, these periodic structures were observed on the coating surface even after one laser pulse.

A profilometer analysis of the sample for the range of laser pulses applied is presented in figure 8. As is observed, more pulses caused deeper damage. A maximum depth of about $10 \mu \mathrm{m}$ was reached with 100 accumulated laser pulses, giving the rate of ablation of $0.1 \mu \mathrm{m} /$ pulse. This investigation confirmed that Nd:YAG laser radiation ablated the TiAlN/TiN multilayer coating with 30 pulses. With further pulses, the laser interacted with the steel substrate.

All irradiations were accompanied by the appearance of spark-like plasma in front of the sample.

The physical processes involved in the interaction of the picosecond Nd:YAG laser pulses with TiAlN/TiN multilayered coating/steel are very complex. With low fluences it is known that, for pulses longer than $10 \mathrm{ps}$, a focused laser beam can 

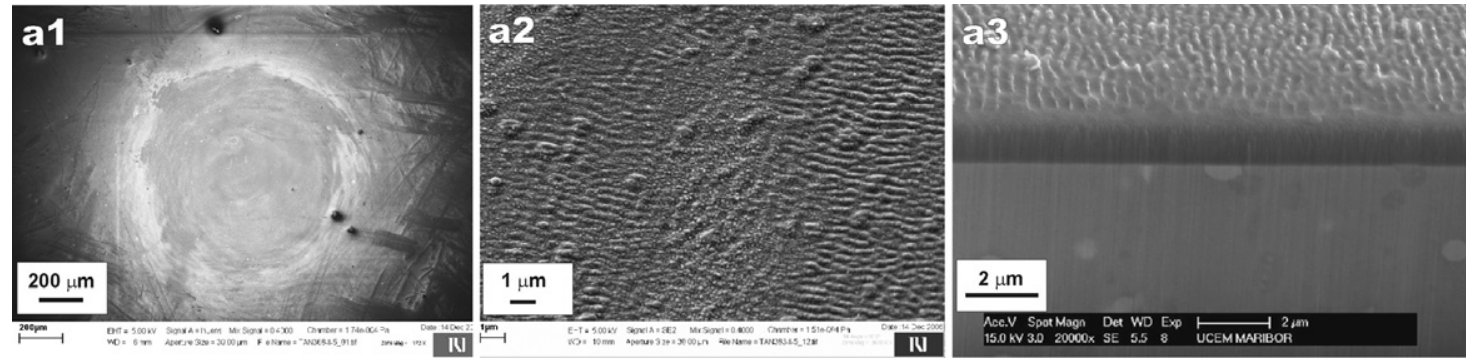

Figure 6. SEM and FIB analysis of the samples irradiated by 10 pulses of the Nd:YAG laser at $532 \mathrm{~nm}$ and fluence $F=0.5 \mathrm{~J} \mathrm{~cm}{ }^{-2}$ : (a1) entire spot (SEM); (a2) central part with periodic structures (SEM); (a3) cross section of the central region (FIB).
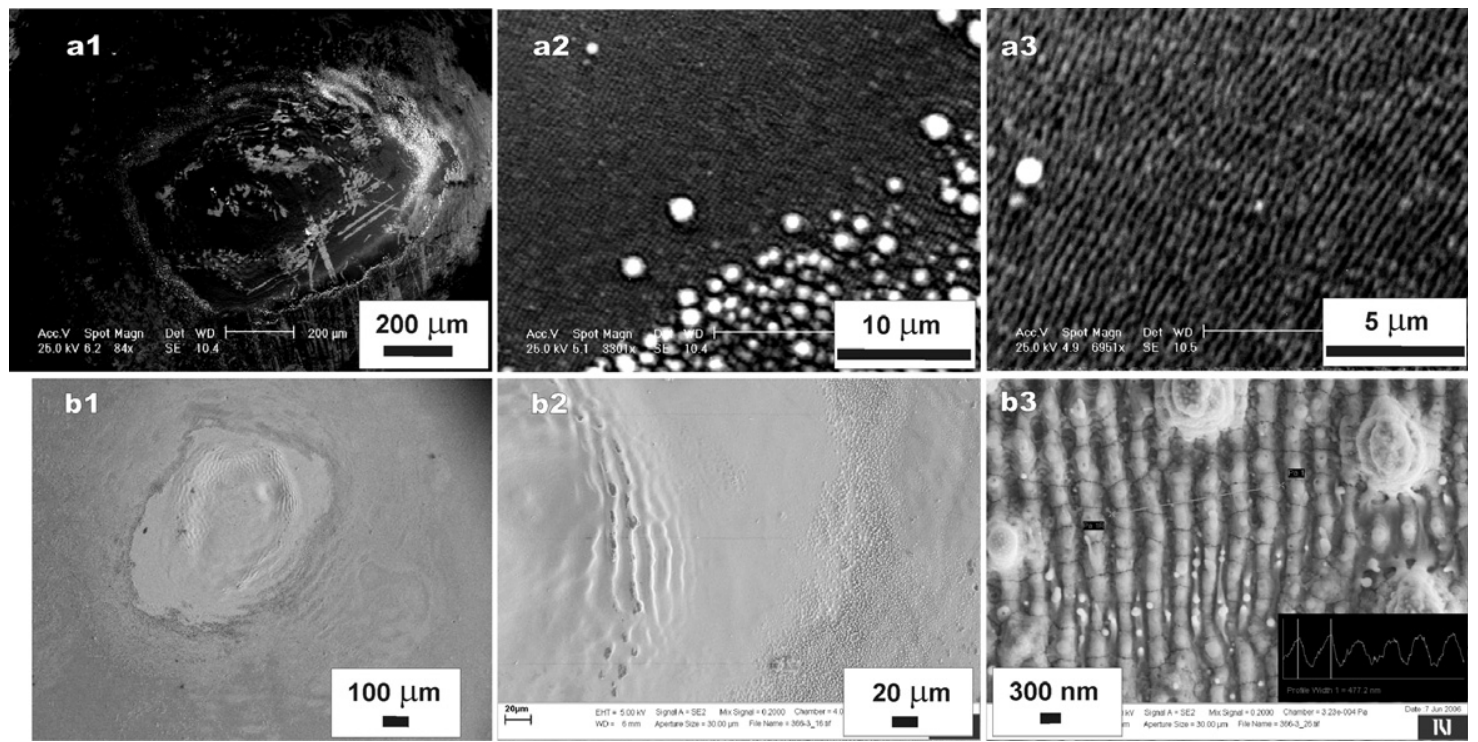

Figure 7. SEM analysis of the TiAlN/TiN coating after Nd:YAG laser irradiation at $532 \mathrm{~nm}$ and fluence of $F=11 \mathrm{~J} \mathrm{~cm}^{-2}$ : (a) after 10 pulses (a1-entire spot; a2 - periphery; a3 — detail from a2); (b) coating after 100 laser pulses (b1—entire spot; b2 - periphery of the ablated spot area; b3 - detail from periphery with periodic structures).

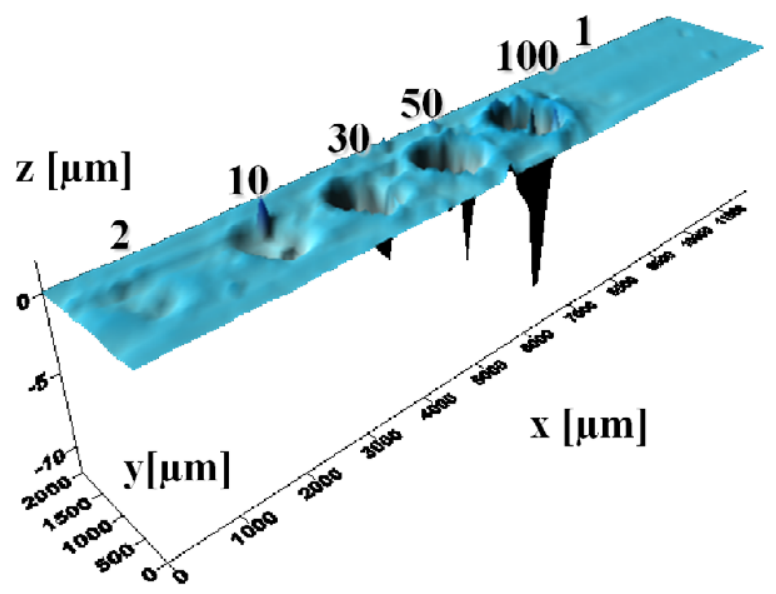

Figure 8. Profilometric 3D view of the sample surface after Nd:YAG laser irradiation at a fluence of $F=11 \mathrm{~J} \mathrm{~cm}^{-2}$. Pulse counts from 1 to 100 are indicated.

be considered as a surface thermal source (electron and lattice temperatures equalize). During irradiation of metals the laser energy is absorbed primarily by free electrons. The absorbed radiation energy in the skin layer involves thermalization within the electron subsystem. Due to electron thermal diffusion, energy transfers to the lattice and heat is transported into the metal. In this simplified picture, in the absence of phase transitions, fast heating and cooling are present. The heat-affected zone (HAZ), roughly the maximum of the radiation absorption length $\left(L_{\mathrm{opt}}\right)$, and the thermal diffusivity length $\left(L_{\mathrm{th}}\right)$ are important parameters for precise/defined laser surface modification [5]. For TiN, $L_{\mathrm{opt}} \approx 30 \mathrm{~nm}$ at the wavelength of $532 \mathrm{~nm}$ [11] and $L_{\text {th }} \approx 16 \mathrm{~nm}$. Since TiAlN/TiN coating can be assumed to have similar properties, this small thickness of the HAZ means that at low laser fluence and low pulse count the coating was surface-modified, but the steel substrate was left intact. With higher fluences and higher pulse count a series of effects such as melting, vaporization, dissociation, ionization of evaporated material, plasma appearance, etc, can be generated. The consequences in the present case were ablation/removal of the coating and substrate modification.

\section{Conclusion}

Two different pulsed lasers, a TEA $\mathrm{CO}_{2}$ laser at $10.6 \mu \mathrm{m}$ (100 ns pulses) and an Nd:YAG laser at $532 \mathrm{~nm}$ (40 ps pulses), 
were used to irradiate a $2.17 \mu \mathrm{m}$ thick multilayered TiAlN/TiN coating deposited on $\mathrm{H} 11$ work-steel. For comparison purposes, the fluences of the lasers were similar, $F=$ $13 \mathrm{~J} \mathrm{~cm}^{-2}$ for the TEA $\mathrm{CO}_{2}$ laser and $F=11 \mathrm{~J} \mathrm{~cm}^{-2}$ for the Nd:YAG laser. Sample surfaces were characterized before and after laser irradiation by an optical microscope, scanning electron microscope (SEM), focused ion beam (FIB) microscope and profilometry.

The obtained effects were qualitatively similar, but quantitatively different. Higher pulse counts produced ablation of the coating in both cases, but only 30 pulses were needed with the Nd:YAG laser, compared to 660 pulses with the TEA $\mathrm{CO}_{2}$ laser. Pulse counts above these created craters in the substrate, with increasing depth as the count increased.

At all pulse counts laser-induced periodic surface structures were created on the coating, with periodicities very close to the laser wavelengths used. This effect was observed even with one pulse of an Nd:YAG at $F=11 \mathrm{~J} \mathrm{~cm}^{-2}$. Also, such a structure was practically the only important feature induced on the target at $F=0.5 \mathrm{~J} \mathrm{~cm}^{-2}$ of the same laser. At lower pulse counts this effect was observable in the centre of the irradiated zone, whereas at higher counts, where the centre undergoes damage, the periodic structures were observed at the periphery on the remaining coating. These structures are assumed to originate from the surface electromagnetic waves created, because the periods of these structures strongly depended on the laser wavelength used.

\section{Acknowledgment}

This research was supported by the Ministry of Science of the Republic of Serbia (contract no. 142065).

\section{References}

[1] PalDay S and Deevi S C 2003 Mater. Sci. Eng. A 34258

[2] Andersen K N, Bienk E J, Schweiz K O, Reitz H, Chevallier J, Kringhoj P and Bottiger J 2000 Surf. Coat. Technol. 123219

[3] Yoo Y H, Le D P, Kim J G and Vinh P V 2007 Thin Solid Films 5163544
[4] Chen L, Du Y, Yin F and Li J 2007 Int. J. Refract. Met. Hard Mater. 2572

[5] Bauerle D 1996 Laser Processing and Chemistry (Berlin: Springer)

[6] Von der Linde D and Sokolowski-Tinten K 2000 Appl. Surf. Sci. 154/155 1

[7] Chickov B N, Moma C, Nolte S, Von Alvensleben F and Tunnermann A 1996 Appl. Phys. A 63109

[8] Moma C, Chickov B N, Nolte S, Von Alvensleben F, Tunnermann A, Welling H and Wellegehausen B 1996 Opt. Commun. 129134

[9] Vouagner D, Beleznai Cs, Girardeau-Montaut J P, Templier C and Gonnord H 2000 Diamond Relat. Mater. 9786

[10] Kononenko T V, Garnov S V, Pimenov S M, Konov V I, Romano V, Borsos B and Weber H P 2000 Appl. Phys. A 71627

[11] Gaković B, Trtica M, Batani D, Desai T, Panjan P and Vasiljevic-Radovic D 2007 J. Opt. A: Pure Appl. Opt. 9 S76

[12] Bonse J, Sturm H, Schmidt D and Kautek W 2000 Appl. Phys. A 71657

[13] Yasumaru N, Miyazaki K and Kiuchi J 2003 Appl. Phys. A 76983

[14] Trtica M S, Tarasenko V F, Gakovic B M, Fedenev A V, Petkovska Lj T, Radak B B, Lipatov E I and Shulepov M A 2005 Appl. Surf. Sci. 252474

[15] Panjan M, Cekada M, Panjan P, Zalar A and Peterman T 2008 Vacuum 82158

[16] Faenov A, Magunov A, Pikuz T, Batani D, Lucchini G, Canova F and Piselli M 2004 Laser Part. Beams 22373

[17] Petrovic S, Gakovic B, Trtica M and Nenadovic T 2001 Laser Part. Beams 19195

[18] Bauerle D 1996 Laser Processing and Chemistry Part V (Berlin: Springer)

[19] Eommony D C, Howson R P and Willis L J 1973 Appl. Phys. Lett. 23598

[20] Guosheng Z, Fauchet P M and Siegman A E 1982 Phys. Rev. B 265366

[21] Sipe J E, Yong J F, Preston J S and van Driel H M 1983 Theor. Phys. Rev. B 271141

[22] Young J F, Sipe J E and van Driel H M 1984 Phys. Rev. B 302001

[23] Semak V V, Thomas J G and Campbell B R 2004 J. Phys. D: Appl. Phys. 372925

[24] Trtica M S, Radak B B, Gakovic B M, Milovanovic D S, Batani D and Desai T 2009 Surface modifications of Ti6Al4V by a picosecond Nd:YAG laser Laser Part. Beams 271 at press 